\title{
Gender Differential in the Incidence of Diabetes Mellitus Among the Patients in Udi Local Government Area of Enugu State, Nigeria
}

\author{
Bernice N. Chukwu ${ }^{1, *}$, Veronica O. Ezebuiro ${ }^{1, \star *}$, E. S. Samuel ${ }^{1, \star \star *}$, \\ Keyna C. Nwachukwu ${ }^{2, * * * *}$ \\ ${ }^{1}$ Department of Health and Physical Education, University of Nigeria, Nsukka qiaeria \\ ${ }^{2}$ Department of Physical and Health Education, Alvan Ikoku Federal College of /ucat Owerri. \\ Imo State, Nigeria \\ *****Phon: $07030576125,08063130183,08037832109,08^{\circ}=06315$

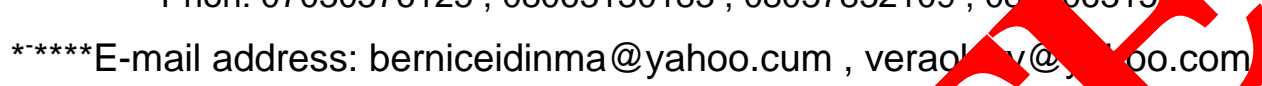 \\ drefiongsamuel@yahoo.com , Keynababy200? oyahoo.c

\section{ABSTRACT}

Diabetes Mellitus is a chronic metabolic dis e characte zed by hyperglycemia and disturbances of carbohydrate, fat and protein metabolis is a $\mathrm{m}$. or public health problem and disease burden worldwide, and especially in N $\mathrm{N}$ ia. This su cermined the gender differential in the incidence of Diabetes mellitus among the $p$ Udi L.G.A of Enugu State. Three research questions and one hypothesis were formulated gy sandudy. Descriptive survey design was employed. A sample of 343 diabetes mallitus patic is were randomly selected and used for the study. Researchers design data documen ary foma w used to collect the data from selected health facilities in respect to the patien ende and their asting sugar level as contained in their folder or hospital record/register. Fregr cy was used to answer research question while the null hypothesis was tested a sing $\mathrm{Ch}$ - are at 0.05 level of significance. The finding of the result revealed a high incidenc a iabetes Me s in 2012, females recorded a high incidence of DM from 2008-2012 and high p centa f fasting blood sugar level than male. The finding also revealed no difference in the fo $\mathrm{mg}_{\mathrm{g}}$ blood su based on gender. It is recommended among others that diagnostic investigation or hum placental actose is advocated to reduce or stop its opposition to insulin secretion dur regp any.

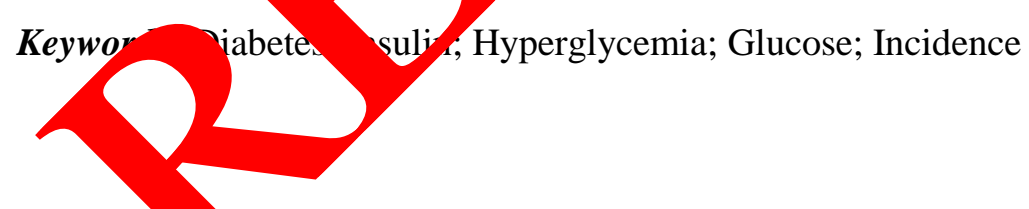

\section{INTR YCTION}

Diabetes mellitus is a chronic metabolic disease characterized by hyperglycemia and by disturbances of carbohydrate, fat, and protein metabolism. It is defined as a chronic disease that occurs either when the pancreas does not produce enough insulin or when the body cannot effectively use the insulin it produces (World Health Organization-WHO \& International Diabetes Federation-IDF, 2006). It is associated with an absolute or relative deficiency in the secretion and /or action of the hormone insulin (Alberto \& Swapnil, 2001). The blood sugar concentration or blood glucose level is the amount of sugar present in the 
blood of an individual. In man, the body maintains the blood glucose level at a range between about 3.6 and $5.8 \mathrm{~mm}$ (mmol/L, i.e., millimoles/liter), or 82 and $110 \mathrm{mg} / \mathrm{dL}$ (Ogbera, Chinenye, Onyekwere \& Fasanmade, 2007). The blood sugar levels outside the normal range are indication of a medical condition. A persistently high level is referred to as hyperglycemia; low level is referred to as hypoglycemia and, if not given proper medical care is inimical to health. Diabetes mellitus is characterized by persistent hyperglycemia and is the most prominent disease related to failure of blood sugar regulation (WHO \& IDF, 2006).

The number of diabetic cases worldwide has increased significantly in the last decade and it is the fifth leading cause of death worldwide (Wild, Roglic, Green, Sicree $b$-King, 2004), and has been noted that one in twenty adult deaths in developing countrie s is dita s related (Gojka. Nigel, Bennet, Mathers, Tuomiletho, \& Satyatjit, 2005) VHO (20) reported an incidence rate of 300 million people with diabetes in the worl in vear 20 and is projected to increase to 366 million by 2030. There is an increas of the in ance of Diabetes Mellitus in the African population. The global estimate of th umbe f peop with diabetes in Africa was approximately 3million in 1994 and was dy to arough 2-3 fold increase by the year 2010 (Amos, McCarty, \& Zimmet, 1997 Oguntor 2011/submitted that the African region experience the incidence rate of D 8 per cen total of 13.1 million people. Over the past 3 decades, diabetes has been ncrea steadiry in Nigeria. In 2008, Nigeria had an incidence rate of over 12 million cauc patien poulation Reference Bureau, 2008), while the incidence rate was 4.7 per ent of the populat on in 2011 (Oguntola, 2011). WHO and IDF (2006) reported that Nigeria as the great st number of people living with diabetes in Africa. The authors added that betes an its complications impose significant economic consequences on individuals, to nealth systems and countries. The threat is growing; the number of people, and communities afflicted is increasing. This growing threat is an under-appreciate caso poverty and hinders the economic development of many countries (WHO, 2009).

According to WHO \& IDF (20 diabet mellitus is of three main types: type 1, type 2 and gestational diabetes. Ty dia etes also nown as insulin-dependent diabetes mellitus (IDDM), is a severe, chron 'orn caused by insufficient production of insulin and resulting in abnormal $\mathrm{m}$ bolism on bohydrates, fats, and proteins. It appears in childhood or adolescence, is cb rac red by in eased sugar levels in the blood and urine, excessive thirst, frequent urias an, ac as, and wasting. The life expectancy of a child with Type 1 diabetes is as $1, \mathrm{w}$ as seven m $\mathrm{M}$ in rural African country like Nigeria caused mainly by limited acce a ins apd its cost and a lack of infrastructure within the healthcare system. In the USA, nt eight $\mathrm{p}$ cent of Type 1 patients live six years after diagnosis but only one per cen child curr ntly survive six years in sub-Saharan Africa. Type-2 diabetes, also kno $n$ as n-insul dependent diabetes mellitus (NIDDM), is a mild form of diabetes that typ finst in adulthood and is exacerbated by obesity and an inactive lifestyle.

disease often has no symptoms, is usually diagnosed by tests that indicate glucose intolerano is treated with changes in diet and an exercise regimen (WHO \& IDF, 2006). Gestational diabetes is a form of glucose intolerance diagnosed during pregnancy. It is common among obese women and women with a family history of diabetes. After pregnancy, 5 to 10 per cent of women with gestational diabetes are found to have type 2 diabetes. Also, women who had gestational diabetes have a 35 to 60 per cent chance of developing diabetes in the next 10-20 years (National Diabetes Statistics NDS, 2011). Popoola (2005) asserted that the most prevalent type of DM in Nigeria is diabetes type 2 or non-insulin-dependent diabetes mellitus (NIDDM) influenced by demographic factors (knowledge of diabetes, diabetes self-support, diabetes self-care management, patient's age, level of education, 
location of clinics, socio-economic status, gender, occupational type, anthropometric parameters and household wealth) influence management of DMT1 and DMT2 among diabetic patients attending clinics and hospitals in Nigeria generally and in Udi LGA in particular.

Incidence means the frequency of occurrences of cases of a disease or spells of illness, or the number of new times something new happens especially a disease (Lucas \& Gilles, 2003). Complex causes of diabetes are in large part due to rapid increases in overweight, obesity and physical inactivity (WHO, 2011).

Clavel (2005) asserted that symptoms of diabetes mellitus may develop quito $f_{9}$ st in type I (insulin dependent) diabetes but may be subtle or completely absen-as wo s developing much more slowly in type II (NIDDM). According to the auth the classi triad of diabetes symptom is polyuria (excessive urination), polydipsia inch d thirs polyphagia (excessive eating), weight loss and irreducible fatigue. Blais (2005) re ed at symptoms of diabetes mellitus include tingling and numbness in $\mathrm{b} d \mathrm{ds}$ an feet of dry skins, sores, more infections than usual, nausea, vomiting or om pain an general irritability. Unexplained weight loss despite adequate food inta e resultin. ingested and digested meals do not get to the target organs $\mathrm{K}$ liver an ascles where they will be utilized or that they get there but the receptors not tional.

Achalu, (1998) posited that people with diabetes oxp rience so 1/weakness, delivery of large babies, still births or recurrent abortion i women, becom/ng tired/weak/fatigue despite adequate and balanced food intake and wh you have n tone any strenuous task. Weakness in diabetes results from non utilization o 'ucose by he organs of the body. In a like manner, diabetes is an immunosuppresaive disora 1. is all due to hyperglycaemia's toxicity on the immune system. Similarly, skin infection is another symptom of diabetes and it even becomes more common whe r. slood sugar raises so much, wounds that are slow to heal, particularly soras on the et and ankles, and recurrent vaginal infection (in women), are signs of possib e dic tes tha are somewhat more likely to draw attention and result in a diagnosis. The ay le do seve e consequences and complications.

Consequences of DN ge t, awn to WHO and IDF (2006), include damage to the heart, blood vessels es, kidne, and nerves; diabetes increases the risk of heart disease and stroke. Fifty per cen people th diabetes die of cardiovascular disease (primarily heart disease and crove). Co ined with reduced blood flow, neuropathy in the feet increases the chance of $f$ ot ulcers and a tual limb amputation. Diabetic retinopathy is an important cause of blip ess, a occurs as a result of long-term accumulated damage to the small blood vessels in the a. After 15 years of diabetes, approximately 2 per cent of people become blind, bout er cont develop severe visual impairment. Diabetes is among the leading cau s of iney fan $c ; 10-20$ per cent of people with diabetes die of kidney failure. Diabetic neu. th the the the nerves and affects up to 50 per cent of people with diabetes.

a ral factors have been implicated in onset of diabetes mellitus. Harris, Courie, Reiber, b $\%$, Stern and Benneth (1995) reported that genetic susceptibility, age, obesity, sex, pregnancy, diet, stress, low birth weight and exercise are the factors associated with the onset of diabetes. WHO (2000) observed that a genetic element known as Histo-compatility Locus Antigen (HLA) in few individuals triggers diabetes. Another cause of diabetes mellitus is obesity- abnormal fat out of desirable range 18.5 to $24.9 \mathrm{~kg} / \mathrm{m} 2$.

Gender is a strong factor associated with the manifestation of diabetes mellitus. Gender according to Kendra (2013) refers to the personal sexual identity of an individual, regardless of the person's biological and outward sex. Differing societal expectations in different cultures establish the behavioural, psychological and physical attributes that are associated with one 
gender or another. Al - Nazha et al (2004) observed a high increase of DM among males of 29.6 per cent compared to 26.5 per cent in female at Saudi Arabia. Men develop type 2 DM at a high rate than their female counter parts. Oguntola (2011) reported that though men have less weight gain than women, men stand a high risk of developing diabetes more easily and at a young age than women because of the way fat is distributed around their body.

Men have fat around the abdomen (which decreases the bodies sensitivity to insulin) and in the liver than women, who on the other hand tend to carry a greater proportion of their body fat under the skin as well as in thighs and buttocks, which is thought to be less risky for type 2 diabetes and other health problems.

Furthermore, the disparity between men and women could also be due to women nowadays have gone calorie conscious irrespective of age and they regime which encloses regular exercise and balance diet. Likewise, it has heen orved th men of both low and high alcohol consumptions, current and former smers were cia with the increase risk of having diabetes mellitus. (Liu, Yu, Li, Wan Sun, \& Lì L010; Choi \& Shi, 2010).

On the contrary, Albert, Boucher, Hitman and Taylor $(190)$ obser that women are more often affected by diabetes. They suggested that pregna ce ay add to likelihood of developing or having diabetes in women. During preor ncy, betes may manifest in genetically susceptible women. Likewise the cause on diabo in women may be attributed to human placental lactogen secreted by e placenta which opposes the action of insulin (Thomas, 1988).

Al-tamimi and Peterson (1998) observed that men con inue to consume sweetened food, even though they knew about the delaterious im a a on oral and dental tissues while King, Aubert and Herman (1998) a that some of the significant reasons why diabetes mellitus was more predominant amo o $\mathrm{W} / \mathrm{m}$. hen compared to men were ascribed to attention to family priorities and women's ability to exercise in public places based on religious beliefs. Based on the reco ed rise $n$ incidence and the burden of diabetes in Nigeria, it is expedient to asc in th oender d,fferential in the incidence of DM among the patients in Udi LG A of Ep

\section{1. Purpose of the cua}

The purpos this stu is of find out the gender differential in the incidence of DM among the pa ients Udi L. y. A. of Enugu State. Specifically, this study answered the following res hacsio s.

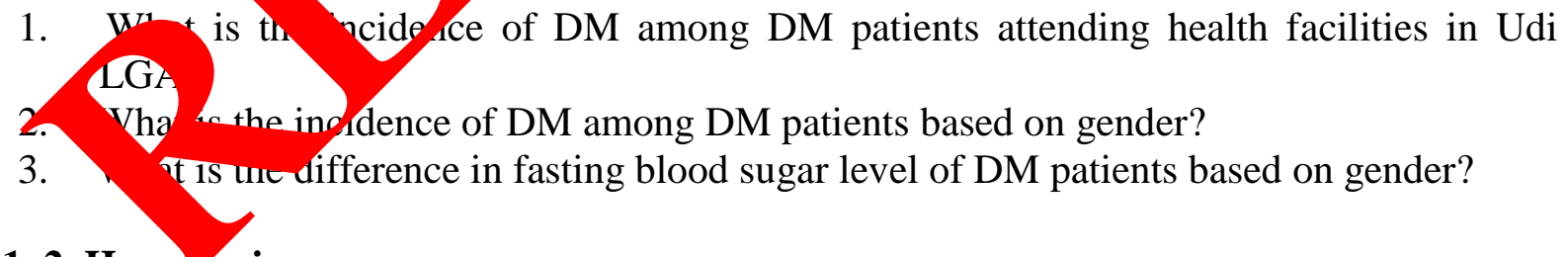

\section{2. Hypo hesis}

The null hypothesis was postulated and tested at 0.05 level of significance. There is no significant difference in the fasting blood sugar level based on gender.

\section{METHODOLOGY}

The study was carried out on diabetes mellitus patients from six health facilities in Udi L. G. A. of Enugu State. A survey research design was used in the study. The population for 
the study comprised of all diabetes mellitus patients who attended health facilities from 20082012 in Udi L.G.A. A sample of 343 Diabetic patients was randomly selected from the health facilities.

The researchers designed a data documentary DM profoma (DMP) for the collection of information concerning cases of Diabetes mellitus in all the selected health facilities in Udi L.G.A. Data from the document provided information in respect of DM patients gender, and the patients' fasting sugar level (FSL) as contained in the patients folder or hospital record/register.

Frequency and percentage was used to answer research questions and chi-squma was used in testing the null hypothesis at 0.05 level of significance.

\section{RESULTS}

The results of the study are presented based on the re ar aestion and the hypothesis. The findings are presented as follows:

\section{Research Question 1}

What is the incidence of DM among patie is in Udi LGA Data answering the question one are contained in Table 1.

Table 1. Frequency and percentages of incidence of D nong pa ents in Udi LGA ( $n=343)$.

Data Table shows tb highest number of diabetes mellitus of 103 cases $(30.0 \%)$ occurred in 24 cases $25.9 \%$ ) in 2011, 71 case $(20.7 \%)$ in 2009 followed by 70 cases $(20.4 \%$ which rred 12010 . The table further shows that 10 cases $(2.9 \%)$ occurred in

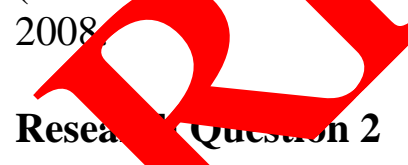

What 1 incidence of DM among Patients in Udi L.G.A based on gender? Data in Table 2 provided the answer to this question. 
Table 2. Incidence of DM among patients based on gender $(n=343)$.

\begin{tabular}{lllll}
\hline Year & \multicolumn{2}{c}{ Male } & \multicolumn{2}{c}{ Female } \\
& F & \% & f & \% \\
\hline 2008 & 4 & 40.0 & 6 & 60.0 \\
2009 & 31 & 43.7 & 40 & 56.3 \\
2010 & 29 & 41.4 & 41 & 58.6 \\
2011 & 40 & 44.9 & 49 & 55.1 \\
2012 & 47 & 45.6 & 56 & 54.4 \\
Total & 151 & 44.0 & 192 & 56.0 \\
\hline
\end{tabular}

Data in Table 3 show that a higher proportion or cases of Diabetes Mu us y as recorded among females $(56.0 \%)$ than the males $(44.0 \%)$. The able ther ss a progressive increase in the incidence of DM from 2008 with the froqu of (mal $=440.0$ $\%)$

\section{Research Question 3}

What is the difference in fasting blood sugar vel of DM pai $1 \mathrm{~s}$ based on gender? Data answering this research question are contained Table 3.

Table 3. Differences in fasting blood sugar level $\mathrm{M}$ patie $\mathrm{ts}$ according to gender.

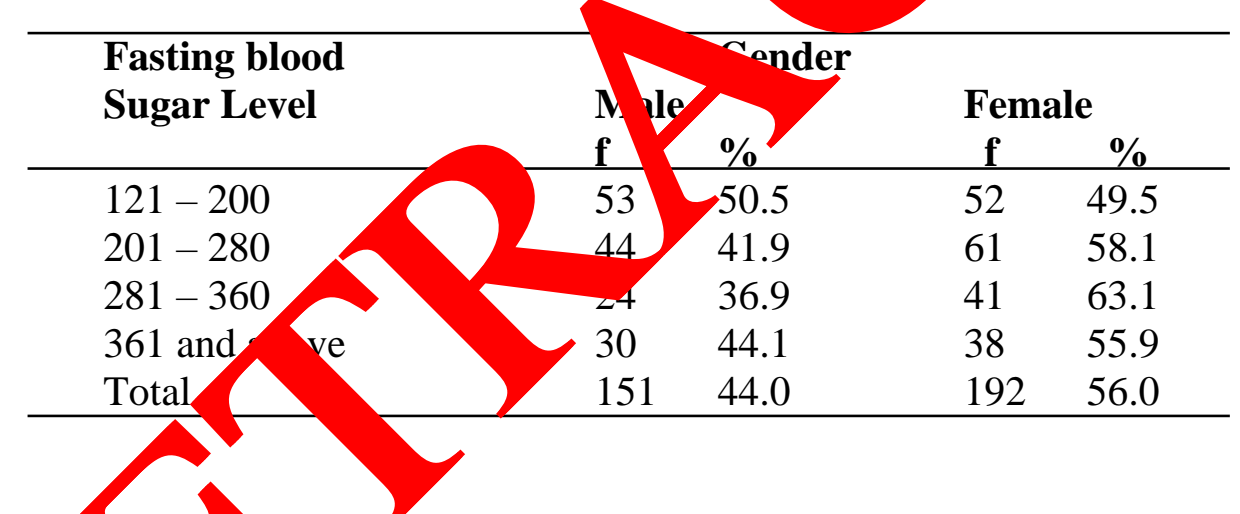

Table bove sury's that female gender $(192,56 \%)$ recorded higher percentage of fasting blood s level an the male gender (151, 44\%). The table further indicates that amono femalo nd 1 , FBSL is move pronounced on $201-280 \mathrm{mg} / \mathrm{dl}$ followed by 121 $200 \mathrm{~g} / \mathrm{dl}$.

\section{Hypot, is 1}

Ther s no significant difference in the fasting blood sugar level based on gender.Data testing this hypothesis are contained on Table 4.

Table 4 shows a calculated $x^{2}$ value of 3.295 at 3 degrees of freedom with a $P$. value of .348 which is more than .05 level of significance. The null hypothesis that there is no significant difference in the fasting blood sugar level based on gender is therefore accepted. This therefore implies that there is no significance difference in the fasting blood sugar level based on gender. Fasting blood sugar level does not differ based on gender 
Table 4. Summary of chi-square $x^{2}$ analysis testing the null hypothesis of no significant difference in the fasting blood sugar level based on gender.

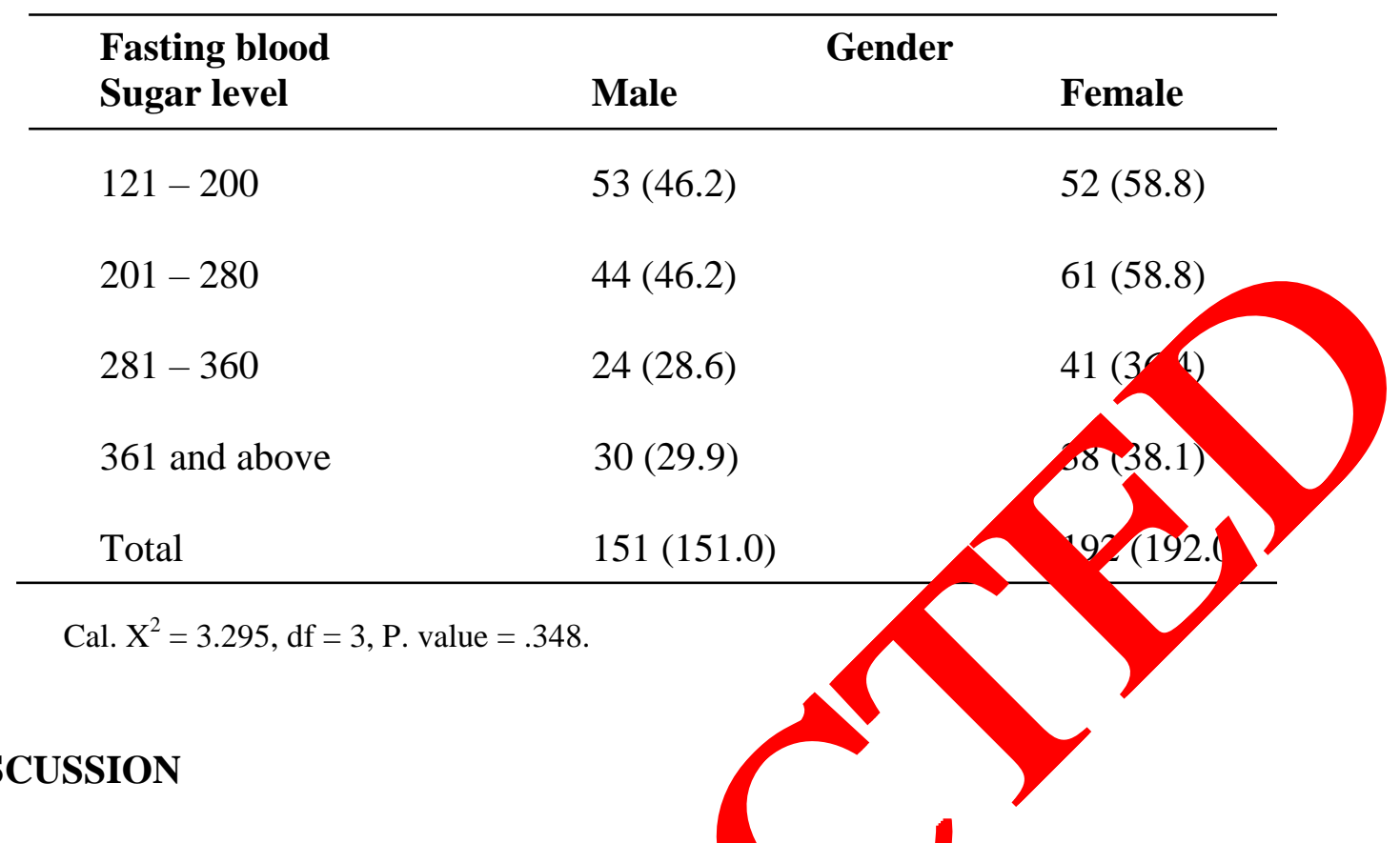

The finding in Table 1 indicated a progress increase $i n$ the incidence of diabetes mellitus. 2012 recorded the highest incidence with freau ncy of 103 (30.0\%) cases of diabetes mellitus in Udi LGA. This result it acted anu not surprising because it is in line with the findings of WHO \& IDF (2006) who repy Nigeria has the greatest number of people living with Diabetes in Africa. The nding on this progressive increase in the incidence may be because of qual food $\mathrm{w}$ ch is majorly carbohydrate and fat consumed by this people. Garri and Aba (Af can sala/which is made from cassava, and yam are the stable food in the area As the carbohydrate, it may be that they do not exercise to burn off exc ss glucos hereby leading to the storage of excess glucose in the body.

The finding in Cable evealed that females recorded a higher incidence of Diabetes mellitus from $2008<2012$ tha des. The result is expected and not surprising. This can be attributed to $t^{\prime}$ e fact hat the fe, nale are in charge of the kitchen and food. Some women eat while they co be ood a d some eat junk starchy food in between meals combined with the starchy fand that more able in the home. This is supported with the finding of Al-tamimi and reter (1990 observed that women continue to consume sweetened food, even th the knew about the deleterious impact of sugar on oral and dental tissues. King, Aube arman (1998) alluded that some of the significant reasons why diabetes mellitus was mor redominant among women when compared to men were ascribed to attention to family prio res and women's inability to exercise in public places based on religious beliefs.

The finding in Table 3 revealed that female recorded a higher percentage of fasting blood sugar level than male. This is not surprising because Albert et. al (1990) observed that women are more often affected by diabetes. They suggested that pregnancy may add to the likelihood of developing or having diabetes in women. During pregnancy, diabetes may manifest in genetically susceptible women. More so, the study of Thomas (1988) revealed that the cause of the diabetes in women may be attributed to human placental lactogen secreted by the placenta which opposes the action of insulin. 
The finding in Table 4 revealed no significant difference in the fasting blood sugar level based on gender. This finding is expected and not surprising because both the males and the females in the study area consume the same stable food which is mostly carbohydrate or starchy food such as garri, rice and yam. Experience has shown that these people have several joints where they sit and drink sometimes all through the day. This factor has prevented them from engaging in exercises which will help to burn excess glucose the blood stream.

\section{CONCLUSIONS}

Based on the findings and discussions, it was concluded that:

1 There is a high incidence case of diabetes mellitus in 2012 in Udi L.C

2 Incidence of Diabetes mellitus was more on female than the male.

3 Female recorded a higher percentage of fasting blood sugar level

4 There is no significant difference in the fasting blood sugar le

\section{Recommendations}

Based on the findings, discussions and conclusi... the foll ing recommendations were made:

1 Sensitization of the general public on Diabet mellitus is aramount in view of its high increase and burden to Nigeria.

2 Health education of the public on th ansequen consumption of excessive caloric food without exercises is imp can diabetes.

3 Diabetes prevention and control progr ns are u, ently needed especially among pregnant women to reduce urden o diabetes mellitus.

4 Diagnostic investigation on hu an place lactose is advocated to reduce or stop its opposition to insulin sec ion Luino nregnancy.

\section{References}

[1] Achalu E. 998 Commum ale and non-communicable diseases, Cause and prevent Ibad Africar Link Books.

[2] Albert K. G. M., B ucher B. J., Hitman G. A., Taylor R. (1990). Diabetes Mellitus. In: Tus ease. D ro: Balliere Tindall.Metabolic and Molecular Basis of Acquired Tiseas . London Belliere Tindall.

[3] A. to B., Swapnil R., Rev. Paron Salud Publica/Pan Am J Public Health 10(5) (2001) $300-$

[4] Al-Nozha, M .M., Al-Maatoug M. A, Al-Mazrou Y. Y, et al. (2004). Diabetes mellitus in Saudi Arabia 25:1603-1610. America. (2nd ed.). Washington D.C: U.S. Government Printing Office.

[5] Al-tamimi S., Peterson P., Int. Dent. J. 48 (30) (1998) 180-6.

[6] Amos A. F., McCarty D. J., Zimmet P., Diabet Med 14 (1997) 1-85. 
[7] Blaise (2005). Causes and prevention of diabetes.

http://www.blaiseweb.com/artcle/d/i/Diabetes html (Retrieved $18^{\text {th }}$ January 2011.from African Americans. Holistic Nurse Practice, 19 10-16.

[8] Choi B. C., Shi F. (2010). Risk factors for diabetes mellitus by age and sex: result of the National Population Health Survey. Retrieved on $4^{\text {th }}$ Jan 2013 from www.ncbi.nlm.nih.gov/pub med/11692170

[9] Clavel M. C. (2005). Mayo clinic on managing diabetes. New York: Kensington Publishing Corporation.

[10] Gojka R. U., Nigel P., Bennet C., Mathers J., Tuomilehto \& Satyajit N., Di betes Ca. 28 (2005) 2130-2135.

[11] Harris M. I., ; Courie C. C., Reiber G., Bonko E., Stern M., Benneth R . 995 in America. $\left(2^{\text {nd }}\right.$ ed). Washington DC: U.S. Government Printing office.

[12] Hornby A. S. (2001). Oxford Advanced Learner's Dictionary Oxford: Oxford University Press.

[13] Kendra C. (2013). What is gender? About.com Guide etri $16 / 06 / 2,13$ from http://psychology.about.com/od/gindex/g/gender.h

[14] King H., Aubert R. E., Herman W. H., Diabete Care 21 (1998) 1,14-1431.

[15] Lucas A. O., Gilles H. M. (2003). Short textbo of public h alth medicine for the tropics $\left(4^{\text {th }} \mathrm{Ed}\right.$.). Ibadan: Bookpower ELST.

[16] Liu C., Yu Z., Li H/, Wang J., Sun L., _in X. (2010). Association of alcohol consumption with diabetes mellitus an im an asting glycaemia among middleaged and elderly Chinese. Retrieved fro www.biomed central.com/1471 $2458 / 10 / 713$.

[17] National Diabetes Stati 10 01 aratiolal diabetes information clearinghouse. Retrieved on $24^{\text {th }} \mathrm{Fe}^{2}, 2013$ http://aiabetes.niddk.nih.gov/dm/pubs/statistics

[18] Ogbera A., Chin ny Onyeku Ć A., Fasanmade O., Ethnicity Dis. 17 (2007) 721-725.

[19] Oguntola 0. (2011). Why in develop diabetes more easily than women. Retrieved Septep 16, 2 from www.tribune. com. ng./index.php/ your - health.

[20] Ponaola M. Holi iic Nurse Practice 19 (2005) 10-16.

[21 Popu tion Rey ence Bureau (2008). World population data sheet.

tp. J.org/pdf08/WPDS_Eng.pdf. Retrieved October 17, 2011.

[22] Th s B. (Ed.) (1988). Dietary management of children with diabetes mellitus. Oxfo, Blackwell Scientific Pub.

[23] WHO (2000). Global water supply and sanitation assessment 2000 report. London: Earthscan Publication Limited.

[24] WHO (2009). WHO, African region: Nigeria. Retrieved from http://www.who.int/countries/nga/areas/hiv/en/index.html on October 17, 2011.

[25] WHO (2011). Diabetes: Fact sheet. Retrieved from http://www.who.int/mediacentre/factsheets/fs312/en/index.html on October 17, 2011. 
[26] Wild S., Roglic G., Green A., Sicree R., King H., Diabetes Care 27 (2004) 1047-1053.

[27] World Health Organization (2010). Department of Non Communicable Disease surveillance Definition, Diagnosis and Classification of Diabetes Mellitus and its Complications. Retrieved 18th March, 2011.

[28] World Health Organization-WHO and International Diabetes Federation-IDF (2006). Definition and diagnosis of diabetes mellitus and intermediate hyperglycemia: Report of a WHO/IDF consultation. Geneva: WHO.

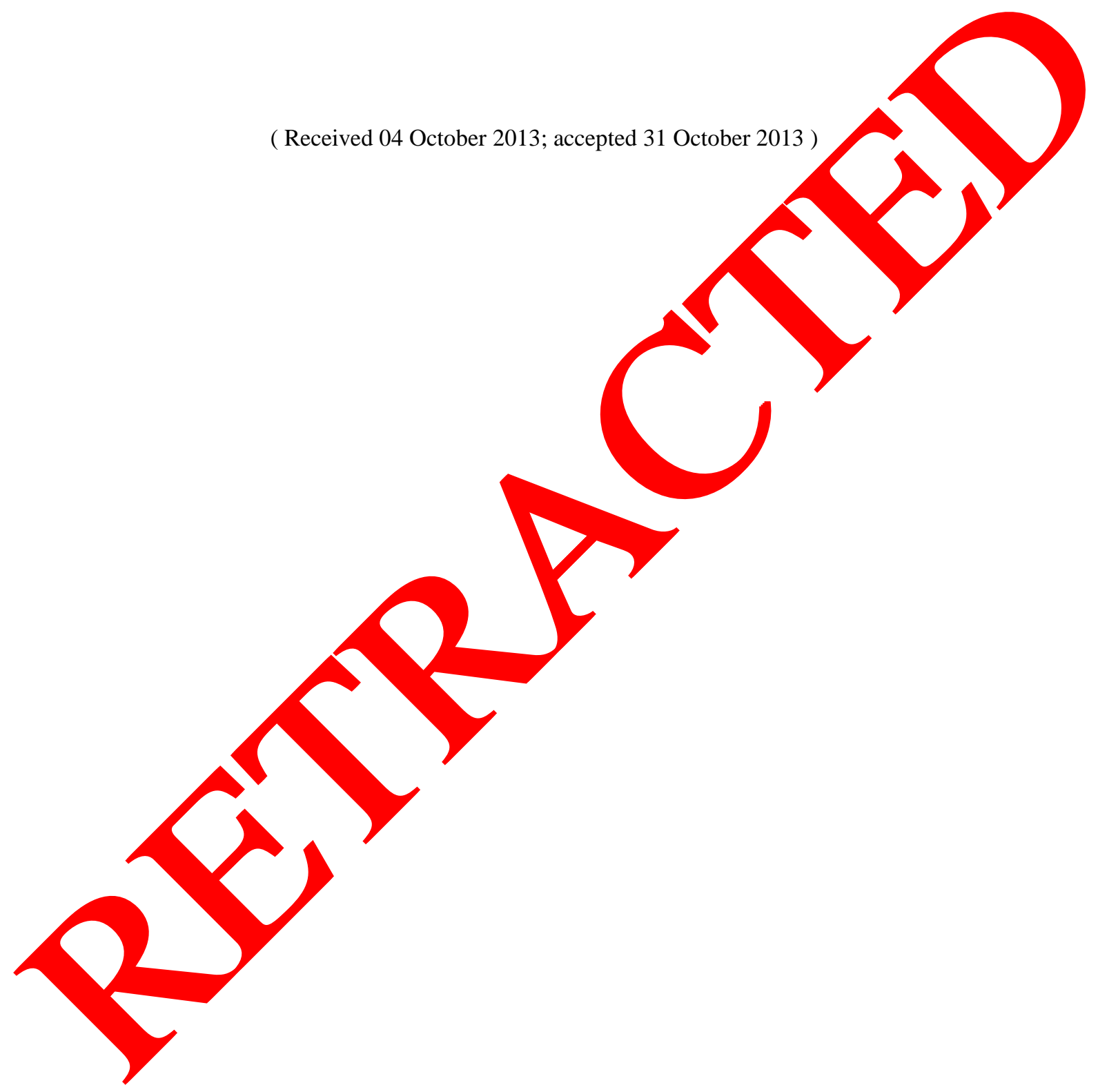

